\title{
STUDI PERSEPSI KEPEMIMPINAN YANG POSITIF, KEPEMIMPINAN YANG MENDUKUNG, PERSEPSI KARYAWAN YANG POSITIF DAN BERPENGARUH TERHADAP PRODUKTIVITAS SUMBER DAYA MANUSIA PADA KARYAWAN PT.WAHANA KASIH MULIA
}

\author{
Didik Subiyanto $^{1}$, Jajuk Herawati ${ }^{2}$, Ade Tursino ${ }^{3}$ \\ ${ }^{1,2,3}$ Fakultas Ekonomi, Universitas Sarjanawiyata Tamansiswa \\ Corresponding author : didiks@ustjogja.ac.id
}

\begin{abstract}
This study aims to analyze the influence of positive perceptions of leadership, supportive leadership, positive employee perceptions and affect HR productivity. The sample of this research is employees who work at PT.WAHANA KASIH MULIA. The method in this study using the Accidental Sampling method. This research is a quantitative research, the sample in this study is 100 employees. The results showed that employee perceptions had a positive and significant effect on positive employee perceptions, supportive leadership had a positive and significant effect on positive employee perceptions, employee perceptions had a positive and significant effect on HR productivity, positive leadership perceptions had no positive and significant effect. Human resource productivity is significant, supportive leadership has a positive and significant effect on HR productivity, positive employee perceptions of $H R$ productivity with positive employee perceptions as an intervention variable have a positive and significant effect and leadership supports $H R$ productivity with positive employee perceptions as a variable which has no positive and significant effect on the employees of PT.WAHANA KASIH MULIA.
\end{abstract}

\section{PENDAHULUAN Latar belakang}

Perkembangan teknologi pada era saat ini membuat persaingan antara perusahaan semakin tingi, persaingan antar perusahaan terjadi karena tingkat perkembangan ekonomi yang besar serta perkembangan jumlah permintaan yang semakin tinggi membuat munculnya bermacam-macam perusahaan yang hanya menjawab kebutuhan konsumen saja. Hal tersebut membuat persaingan antar perusahaan semin ketat, terutama pada industri yang sejenis. Perubahan selera konsumen dari waktu ke waktu, kemajuan teknologi yang begitu cepat serta perubahan sosial ekonomi membuat berbagai kesempatan dan tantangan serta ancaman dalam berbagai sektor bisnis di segala bidang. Begitu juga yang terjadi pada industri tekstil dan garmen pada PT.WAHANA KASIH MULIA, persaingan yang terjadi tidak hanya produk dalam negeri saja akan tetapi juga produk luar negeri yang lebih kompetitif pada bahan baku, motiv produk, serta harga. Perusahaan yang bergerak dalam bidang penjualan yang memiliki kapasitas besar, tentunya memerlukan karyawan dalam jumlah yang banyak. Dengan demikian faktor sumber daya manusia yang ada harus diperhatikan dan dikelola dengan sebaik-baiknya 
agar dapat bekerja secara optimal dan maksimal serta kinerja karyawan yang tinggi sehingga misi dan tujuan perusahaan akan tercapai.

Sumber daya manusia memiliki peran yang sangat panting bagi perkembangan suatu organisasi, tanpa adanya sumber daya manusia maka organisasi tidak dapat berjalan dengan baik. Walaupun didukung dengan sarana dan prasarana yang cukup memadai tetapi bila sumber daya manusia tidak memiliki keahlian dalam menggunakan sarana dan prasarana maka tujuan organisasi tersebut tidak dapat tercapai secara maksimal. Hal ini menunjukan bahwa kualitas kinerja tidak bisa dilepaskan dari kemampuan serta kompetensi karyawan dalam menyelesaikan tugasnya, maka dari itu sumber daya manusia merupakan kunci keberhasilan organisasi dalam menyelesaikan tugasnya (Findarti, 2016).

\section{LANDASAN TEORI DAN PENGEMBANGAN HIPOTESIS Persepsi Kepemimpinan yang Positif}

Persepsi kepemimpinan yang positif ialah model kepemimpinan yang akan membuat para karyawan termotivasi untuk bekerja lebih baik sehingga produktivitas suatu perusahaan akan meningkat. Menurut Hater \& Bass (1988) dalam (Anggraeni \& Santosa, 2013) menyatakan bahwa pemimpin transformasional merupakan pemimpin yang memiliki kharismatik serta memiliki kedudukan yang sentral dan strategis dalam memimpin. Kepemimpinan yang positif di suatu perusahaan diharapkan dapat menaikan kualitas kerja karyawan sehingga akan menaikan produktivitas perusahaan.

\section{Faktor-faktor persepsi kepemimpinan yang positif}

Persepsi kepemimpinan yang positif merupakan cara seorang pemimpin untuk membangun hubungan yang baik dengan karyawan. Persepsi kepemimpinan yang positif membangun hubungan dengan karyawan dengan cara mengembangkan kepercayaan karyawan, kreatifitas, motivasi dll. Menurut Bass dan Avolio (1990) dalam (Euis, 2008), terdapat 4 faktor yang mendasari persepsi kepemimpinan yang positif yaitu : pemimpin yang kharismatik, pemimpin yang inspirasional, pemimpin yang dapat memecahkan masalah/stimulasi intelektual, pemimpin yang dapat bersikap adil terhadap karyawan.

\section{Kepemimpinan yang Mendukung}

Kepemimpinan yang mendukung merupkan kepemimpinan yang memberikan motivasi karyawannya serta memberi imbalan, dengan cara begitu maka karyawan akan merasa terpacu untuk bekerja dengan baik. Kepemimpinan mendukung ialah kepemimpinan yang dapat memberikan motivasi kepada bawahannya dengan menyerukan ketertarikan mereka. Kepemimpinan ini merupakan gaya kepmipinan yang harus menyesuaikan perilaku dan sikap karyawannya (Thomas \& Vethouse, 2003) dalam (Jufrizen \& Lubis, 2020).

\section{Faktor-faktor kepemimpinan yang mendukung.}

Kepemimpinan yang mendukung merupakan hubungan antara pemimpin dan karyawan dalam melakukan pekerjaan sehingga visi dan misi perusahaan akan tercapai dengan baik. Menurut burns (1978) dalam (Euis, 2008) kepemimpinan yang mendukung merupakan cara seorang pemimpin untuk memotivasi karyawannya agar lebih giat dalam bekerja dengan cara memberikan reward. Faktor kepemimpinan 
yang mendukung yaitu : memberikan reward kepada karyawan, mengawasi karyawan dalam bekerja, keamanan dalam bekerja, memberikan pelatihan.

\section{Persepsi Karyawan yang Positif}

Pentingnya suatu perusahaan memiliki lingkungan dan keselamatan kerja yang baik. Dengan adanya hal tersebut maka akan meningkatkan kepercayaan karyawan dalam organisasi serta akan meningkatkan efisiensi para karyawan yang akan mengarah pada hasil keseluruhan (Fan dkk.,2004). Jika karyawan merasa aman dan nyaman ditempat kerja, maka mereka akan lebih terlibat dengan organisasi mereka secara emosional serta menganggap pekerjaan itu sebagai tanggung jawab mereka (Singh \& Misra, 2020).

\section{Faktor-faktor persepsi karyawan yang positif.}

Keberhasilan suatu perusahaan tidak akan terlepas dari karyawan sehingga untuk meningkatkan kinerja karyawan maka seorang pemimpin harus memotivasi karyawannya untuk lebih giat lagi dalam bekerja sehingga perusahaan akan mendapatkan hasil yang terbaik(Syafei, Fahmi, \& Hubeis, 2016). Sedarmayanti (2011) menyatakan bahwa lingkungan kerja dibagi menjadi 2 faktor yaitu faktor lingkungan kerja non fisik dan faktor lingkungan kerja fisik. Faktor-faktor yang mempengaruhi persepsi kinerja yang positif yaitu : faktor budaya organisasi, faktor motivasi, faktor kepemimpinan, faktor lingkungan kerja yang nyaman.

\section{Produktivitas SDM}

European Productivity Agency (EPA) mendefinisikan produktivitas dalam dua cara yaitu : 1. Produktivitas mengacu pada tingkat penggunaan setiap elemen produksi, dan 2. Produktivitas mengacu pada jenis pemikiran. Menurut Japan Productivity Center (JPC) produktivitas adalah prioritas dan pilihan nasional, jadi setiap usaha untuk meningkatkan produktivitas akan mengarah pada peningkatan kesejahteraan. Produktivitas merupakan faktor sumber daya manusia dan produksi lainnya dengan tujuan untuk menurunkan harga akhir, meningkatkan nilai pasar, mengurangi pengangguran, meningkatkan pendapatan secara nyata dan meningkatkan standar hidup pelangan, manajer serta karyawan (Mohammadian, Arayesh, Mohammadian, Azizpour, \& Zanganeh, 2011).

\section{Faktor-faktor produktivitas SDM}

Dalam organisasi karyawan merupakan variabel yang banyak dipengaruhi oleh beberapa faktor terutama pada produktivitas (Sedarmayanti, 2001:57) dalam (Nasron \& Astuti, 2011). Produktivitas dipengaruhi oleh beberapa faktor diantaranya yaitu : sikap karyawan dalam melakukan pekerjaan, keterampilan karyawan dalam menyelesaikan tugas, hubungan antara karyawan dan pimpinan organisasi, efisiensi karyawan dalam bekerja. 


\section{MODEL PENELITIAN}

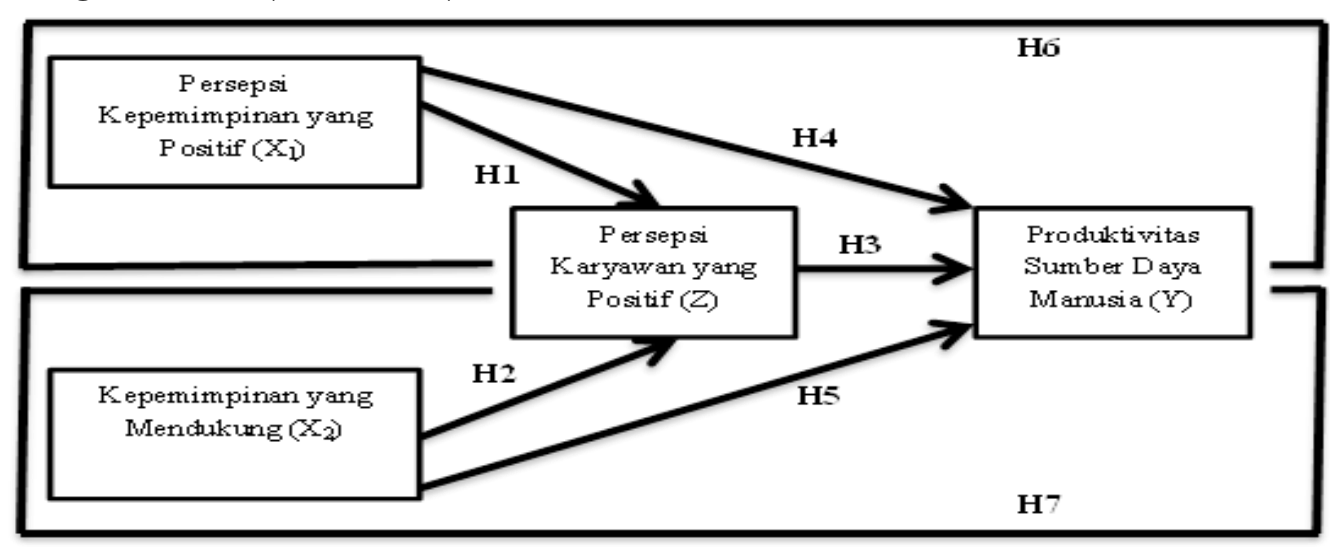

Gambar 1 kerangka pikir penelitian

\section{METODE PENELITIAN}

\section{Populasai dan Sampel}

Sesuai dengan tujuan penelitian ini yakni menganalisis pengaruh persepsi kepemimpinan yang positif, kepemimpinan yang mendukung, persepsi karyawan yang positif berpengaruh terhadap produktivitas sumber daya manusia pada PT.WAHANA KASIH MULIA. Sehingga penelitian ini bersifat deskriptif kuantitatif yaitu penelitian dengan mendeskripsikan ataupun menggambarkan sumber data yang terkumpul berwujud angka-angka ataupun memakai alat statistic.(Prajitno, 2008).

Populasi merupakan sumber informasi yang akan diolah, Arikunto (2006:130) dalam (Nathan \& Scobell, 2012) berpendapat bahwa "populasi ialah sekumpulan unsur elemen yang menjadi objek penelitian".Sampel menurut Sugiyono (2017:81) dalam (Masruroh, 2019), sampel adalah bagian dari jumlah karakteristik yang ada pada populasi tersebut. Sampel penelitian ini adalah karyawan yang bekerja di PT.WAHANA KASIH MULIA. Metode yang digunakan dalam penelitian ini adalah metode slovin menurut (Sanusi, 2011:101) dalam (Wisastra \& Sagala, 2016). Berdasarkan perhitungan menggunakan rumus slovin diatas maka peneliti mengambil sampel sebanyak 100 responden (di bulatkan).

\section{HASIL DAN PEMBAHASAN}

\section{Uji Validitas}

Uji Validitas digunakan untuk mengukur sah atau valid tidaknya suatu kuesioner. Suatu kuesioner dikatakan valid jika suatu pertanyaan kuesioner bisa mengungkapkan sesuatu yang diukur oleh kuesioner tersebut (Imam Ghozali, 2013:52) dalam (Nurcahyo \& Riskayanto, 2018). Sedangkan menurut Sugiyono (2016:177) uji validitas merupakan ketetapan antara informasi yang dikumpulkan degan informasi yang sesungguhnya terjadi pada obyek penelitian. Ketentuan minimum dalam uji validitas jika butir instrument valid yang mempunyai nilai indeks validitasnya $\mathrm{r}_{\text {hitung }}$ lebih besar dari $r_{\text {tabel }}(0.197)$ maka bisa dikatakan valid dan juga sebaliknya jika $r_{\text {hitung }}$ lebih kecil dari $r_{\text {tabel }}$ maka dikatakan tidak valid. Pengujian validitas instrument penelitian (kuesioner) dengan tiap-tiap pertanyaan yang memperoleh nilai $\mathbf{r}_{\text {hitung }}$ lebih besar dari $\mathrm{r}_{\text {tabel }}$ yaitu 0.197. sehingga keseluruhan kuesioner penelitian tersebut bisa dikatakan valid. 


\section{Uji Reliabilitas}

Reliabilitas merupakan suatu alat untuk mengukur kuesioner yang merupakan bagian dari variabel ataupun konstruk di dalam penelitian. Suatu kuesioner penelitian dikatakan reliable ataupun handal jika jawaban seseorang terhadap pernyataan tidak berubah-ubah ataupun normal dari waktu ke waktu (imam Ghozali, 2013: 47) dalam (Nurcahyo \& Riskayanto, 2018). Sedangkan menurut Sugiyono (2013:121) mengatakan bahwa uji reliabilitas merupakan hasil kuesioner yang telah diolah serta hasilnya tidak berubah-ubah setelah dilakukan pengukuran sebanyak dua kali. Untuk mengukur reliabilitas dengan uji statistic Cronbach Alpa (a). Suatu variabel bisa dikatakan reliable jika memberikan nilai a $>0,06$. Hasil penelitian bisa dilihat pada tabel berikut ini :

Tabel 1

Hasil Uji Reliabilitas

\begin{tabular}{lccc}
\hline \multicolumn{1}{c}{ Variabel } & $\begin{array}{c}\text { Cronbach's } \\
\text { Alpha Based on } \\
\text { Standardized } \\
\text { Items }\end{array}$ & $\begin{array}{c}\text { Nilai } \\
\text { Kritis }\end{array}$ & Keterangan \\
& 0.807 & 0.06 & Reliabel \\
\hline Persepsi kepemimpinan yang positif $\left(\mathrm{X}_{1}\right)$ & 0.899 & 0.06 & Reliabel \\
Kepemimpinanan yang mendukung $\left(\mathrm{X}_{2}\right)$ & 0.724 & 0.06 & Reliabel \\
Persepsi karyawan yang positif $(\mathrm{Z})$ & 0.857 & 0.06 & Reliabel \\
Produktivitas SDM (Y) & & & \\
\hline
\end{tabular}

Sumber : Data primer yang diolah peneliti, tahun 2020

Pada data hasil reliabilitas diatas membuktikan bahwa seluruh variabel penelitian yang memiliki koefisien Alpha yang cukup besar yaitu diatas 0,06 sehingga bisa dikatakan seluruh konsep pengukuran tiap-tiap variabel dari kuesioner penelitian ini adalah reliable yang berarti bahwa kuesioner yang digunakan dalam penelitian ini merupakan kuesioner yang reliable atau handal.

\section{Uji Multikolinieritas}

Uji Multikolinieritas bertujuan untuk menguji apakah dalam model regresi ditemukan adanya korelasi antar variabel bebas (independen). Model regresi yang baik seharusnya tidak terjadi korelasi diantara variabel bebas. Untuk mengetahui ada atau tidaknya multikolinearitas di dalam model regresi, ialah dengan melihat nilai tolerance, dan lawannya yaitu variance inflation factor (VTF). Apa bila nilai cut off yang umumnya dipakai untuk membuktikan terdapatnya multikolineritas adalah nilai tolerance $>0,10$, atau sama dengan nilai VTF < 10 maka model regresi yang digunakan dalam penelitian ini bebas dari multikolineritas. (Imam Ghozali,2013:105) tabel berikut ini menyajikan hasil pengujian multikolenearitas : 
Tabel 2

Hasil Uji Multikolinieritas

\begin{tabular}{|c|c|c|c|c|c|c|c|c|}
\hline \multirow{2}{*}{\multicolumn{2}{|c|}{ Model }} & \multicolumn{2}{|c|}{$\begin{array}{l}\text { Unstandardized } \\
\text { Coefficients }\end{array}$} & \multicolumn{2}{|l|}{$\begin{array}{l}\text { Standardized } \\
\text { Coefficients }\end{array}$} & \multicolumn{3}{|c|}{$\begin{array}{l}\text { Collinearity } \\
\text { Statistics } \\
\text { Toler }\end{array}$} \\
\hline & & B & Error & Beta & $\mathrm{t}$ & Sig. & ance & VIF \\
\hline 1 & (Constant) & 25.013 & 3.737 & & 6.693 & .000 & & \\
\hline & $\begin{array}{c}\text { Total Persepsi Kepemimpinan } \\
\text { Yang Positif (X1) }\end{array}$ & .334 & .182 & .265 & 1.833 & .070 & .379 & 2.637 \\
\hline & $\begin{array}{c}\text { Total Kepemimpinan Yang } \\
\text { Mendukung (X2) }\end{array}$ & .190 & .111 & .246 & 1.701 & .092 & .379 & 2.637 \\
\hline
\end{tabular}

a. Dependent Variable: Total Persepsi Karyawan Yang Positif

Sumber : data primer yang diolah, tahun 2020

Berdasarkan pada tabel 2 dari hasil pengujian multikolinearitas, perhitungan nilai tolerance terlihat bahwa variabel persepsi kepemimpinan yang positif mempunyai nilai tolerance sebesar $0.379>0,10$ maka dapat disimpulkan tidak terdapat masalah dalam uji multikolinearitas. Demikian juga dengan hasil perhitungan nilai VIF yang didapatkan dalam penelitian ini sebesar 0.2.637 < 10 maka dapat disimpulkan bahwa tidak terjadi multikolinearitas antara variabel independen dalam model regresi.

Tabel 3

Hasil Uji Multikolinieritas

\begin{tabular}{|c|c|c|c|c|c|c|c|c|}
\hline & \multirow[b]{3}{*}{ Model } & \multicolumn{5}{|c|}{ Coefficients ${ }^{\mathrm{a}}$} & \multirow{2}{*}{\multicolumn{2}{|c|}{$\begin{array}{l}\text { Collinearity } \\
\text { Statistics }\end{array}$}} \\
\hline & & \multicolumn{2}{|c|}{$\begin{array}{l}\text { Unstandardized } \\
\text { Coefficients }\end{array}$} & \multicolumn{2}{|l|}{$\begin{array}{l}\text { Standardized } \\
\text { Coefficients }\end{array}$} & \multirow[b]{2}{*}{ Sig. } & & \\
\hline & & $\mathrm{B}$ & Std. Error & Beta & $\mathrm{T}$ & & Tolerance & VIF \\
\hline \multirow[t]{4}{*}{1} & (Constant) & 15.753 & 5.039 & & 3.126 & .002 & & \\
\hline & $\begin{array}{c}\text { Persepsi } \\
\text { kepemimpinan } \\
\text { yang positif } \\
\text { (x1) }\end{array}$ & .343 & .207 & .202 & 1.657 & .101 & .367 & 2.728 \\
\hline & $\begin{array}{c}\text { Kepemimpinan } \\
\text { yang } \\
\text { mendukung } \\
\text { (X2) }\end{array}$ & .255 & .126 & .246 & 2.020 & .046 & .368 & 2.715 \\
\hline & $\begin{array}{c}\text { Persepsi } \\
\text { karyawan yang } \\
\text { positif }(\mathrm{Z})\end{array}$ & .507 & .113 & .378 & 4.478 & .000 & .767 & 1.303 \\
\hline
\end{tabular}

a. Dependent Variable: Produktivitas SDM (Y)

Sumber : Data primer yang diolah, tahun 2020

Berdasarkan pada tabel 3 dari hasil pengujian multikolinearitas, perhitungan nilai tolerance terlihat bahwa variabel persepsi kepemimpinan yang positif mempunyai nilai tolerance sebesar $0.367>0,10$ maka dapat disimpulkan tidak terdapat masalah dalam uji multikolinearitas. Demikian juga dengan hasil perhitungan nilai VIF yang 
didapatkan dalam penelitian ini sebesar $2.728<10$, kepemimpinan yang mendukung mempunyai nilai tolerance sebesar $0.368>0,10$ maka dapat disimpulkan tidak terdapat masalah dalam uji multikolinearitas.

Demikian juga dengan hasil perhitungan nilai VIF yang didapatkan dalam penelitian ini sebesar $2.715<10$ dan persepsi karyawan yang positif mempunyai nilai tolerance sebesar $0.767>0,10$ maka dapat disimpulkan tidak terdapat masalah dalam uji multikolinearitas. Demikian juga dengan hasil perhitungan nilai VIF yang didapatkan dalam penelitian ini sebesar $1.303<10$, maka dapat disimpulkan bahwa tidak terjadi multikolinearitas antara variabel independen dalam model regresi.

\section{Analisis Regresi}

Hasil regresi persepsi kepemimpinan yang positif, kepemimpinan yang mendukung terhadap persepsi karyawan yang positif.

Tabel 4

Analisis Regresi

\begin{tabular}{|c|c|c|c|c|c|c|}
\hline \multicolumn{7}{|c|}{ Coefficients $^{\mathrm{a}}$} \\
\hline & \multirow[b]{3}{*}{ Model } & \multirow{2}{*}{\multicolumn{2}{|c|}{$\begin{array}{l}\text { Unstandardized } \\
\text { Coefficients }\end{array}$}} & \multirow{2}{*}{$\begin{array}{l}\text { Standardized } \\
\text { Coefficients }\end{array}$} & \multirow[b]{3}{*}{$\mathrm{t}$} & \multirow[b]{3}{*}{ Sig. } \\
\hline & & & & & & \\
\hline & & $\mathrm{B}$ & Std. Error & Beta & & \\
\hline \multirow[t]{3}{*}{1} & (Constant) & 25.013 & 3.737 & & 6.693 & .000 \\
\hline & TotalX1 & .334 & .182 & .265 & 1.833 & .070 \\
\hline & TotalX2 & .190 & .111 & .246 & 1.701 & .092 \\
\hline
\end{tabular}

a. Dependent Variable: TotalZ

Sumber : Data primer yang diolah, tahun 2020

\section{H1 pengaruh persepsi kepemimpinan yang positif terhadap persepsi karyawan yang positif.}

Pada penelitian ini menggunakan Uji $\mathrm{t}$ untuk mengetahui pengaruh persepsi kepemimpinan yang positif terhadap persepsi karyawan yang positif. Hasil Uji t yang dilakukan dalam penelitian ini dengan cara membandingkan nilai $\mathrm{p}$ value dengan nilai $\alpha(0.05)$.

Tingkat signifikansi pada variabel persepsi kepemimpinan yang positif pada t hitung sebesar 1.833 (positif) maka dapat ditarik kesimpulan untuk analisis regresi persepsi kepemimpinan yang positif terhadap persepsi karyawan yang positif dengan nilai t tabel < t hitung $(1.660<1.833)$ serta nilai signifikansi $0.070 / 2=0.035<0.05$, maka $\mathrm{H}_{1}$ diterima.

\section{$\mathrm{H}_{2}$ pengaruh kepemimpinan yang mendukung terhadap persepsi karyawan yang positif}

Pada penelitian ini menggunakan Uji t untuk mengetahui pengaruh kepemimpinan yang mendukung terhadap persepsi karyawan yang positif pada karyawan PT.WAHANA KASIH MULIA. Berdasarkan hasil perhitungan menggunakan SPSS 25 seperti yang terlihat pada tabel diatas dan hasil Uji t yang dilakukan dalam penelitian ini dengan cara membandingkan nilai $p$ value dengan nilai $\alpha(0.05)$.

Tingkat signifikansi pada variabel kepemimpinan yang mendukung pada $t$ hitung sebesar 1.701 (positif) maka dapat ditarik kesimpulan untuk analisis regresi kepemimpinan 
yang mendukung terhadap persepsi karyawan yang positif dengan nilai $\mathrm{t}$ tabel $<\mathrm{t}$ hitung $(1.660<1.701)$ serta nilai signifikansi $0.092 / 2=0.046<0.05$, maka $\mathrm{H}_{2}$ diterima.

Tabel 6

Hasil regresi persepi kepemimpinan yang positif, kepemiminan yang mendukung, persepisi karyawan yang positif terhadap produktivitas SDM

\begin{tabular}{|c|c|c|c|c|c|c|}
\hline \multicolumn{7}{|c|}{ Coefficients $^{\mathbf{a}}$} \\
\hline & & \multirow{2}{*}{\multicolumn{2}{|c|}{$\begin{array}{c}\text { Unstandardized } \\
\text { Coefficients }\end{array}$}} & \multirow{2}{*}{$\begin{array}{l}\text { Standardized } \\
\text { Coefficients }\end{array}$} & \multirow[b]{3}{*}{$\mathrm{t}$} & \multirow[b]{3}{*}{ Sig. } \\
\hline & & & & & & \\
\hline \multicolumn{2}{|r|}{ Model } & $\mathrm{B}$ & Std. Error & Beta & & \\
\hline \multirow[t]{4}{*}{1} & (Constant) & 15.753 & 5.039 & & 3.126 & .002 \\
\hline & TotalX1 & .343 & .207 & .202 & 1.657 & .101 \\
\hline & TotalX2 & .255 & .126 & .246 & 2.020 & .046 \\
\hline & TotalZ & .507 & .113 & .378 & 4.478 & .000 \\
\hline
\end{tabular}

a. Dependent Variable: Total Y

Sumber : Data primer yang dioalh, tahun 2020

\section{$\mathrm{H}_{3}$ pengaruh persepsi karyawan yang positif terhadap produktivitas SDM}

Pada penelitian ini menggunakan Uji t untuk mengetahui pengaruh persepsi kepemimpinan yang positif terhadap produktivitas SDM pada karyawan PT.WAHANA KASIH MULIA. Berdasarkan hasil perhitungan menggunakan SPSS 25 seperti yang terlihat pada tabel diatas dan hasil Uji t yang dilakukan dalam penelitian ini dengan cara membandingkan nilai $p$ value dengan nilai $\alpha(0.05)$.

Tingkat signifikansi pada variabel persepsi kepemimpinan yang positif pada $t$ hitung sebesar 1.657 (negatif) maka dapat ditarik kesimpulan untuk analisis regresi persepsi kepemimpinan yang positif terhadap produktivitas SDM dengan nilai t tabel $<\mathrm{t}$ hitung $(1.660>1.657)$ serta nilai signifikansi $0.101 / 2=0.05$, maka $\mathrm{H}_{3}$ ditolak.

\section{$H_{4}$ kepemimpinan yang mendukung terhadap produktivitas SDM}

Pada penelitian ini menggunakan Uji t untuk mengetahui pengaruh kepemimpinan yang mendukung terhadap produktivitas SDM pada karyawan PT.WAHANA KASIH MULIA. Berdasarkan hasil perhitungan menggunakan SPSS 25 seperti yang terlihat pada tabel diatas dan hasil Uji t yang dilakukan dalam penelitian ini dengan cara membandingkan nilai $p$ value dengan nilai $\alpha(0.05)$.

Tingkat signifikansi pada variabel kepemimpinan yang mendukung pada t hitung sebesar 2.020 (positif) maka dapat ditarik kesimpulan untuk analisis regresi kepemimpinan yang mendukung terhadap produktivitas SDM dengan nilai t tabel $<\mathrm{t}$ hitung $(1.660<2.020)$ serta nilai signifikansi $0.046 / 2=0.023<0.05$, maka $\mathrm{H}_{4}$ diterima.

\section{H5 persepsi karyawan yang positif terhadap produktivitas SDM}

Pada penelitian ini menggunakan Uji t untuk mengetahui pengaruh persepsi karyawan yang positif terhadap produktivitas SDM pada karyawan PT.WAHANA KASIH MULIA. Berdasarkan hasil perhitungan menggunakan SPSS 25 seperti yang 
terlihat pada tabel diatas dan hasil Uji t yang dilakukan dalam penelitian ini dengan cara membandingkan nilai $p$ value dengan nilai $\alpha(0.05)$.

Tingkat signifikansi pada variabel persepsi karyawan yang positif pada t hitung sebesar 4.478 (positif) maka dapat ditarik kesimpulan untuk analisis regresi kepemimpinan yang mendukung terhadap produktivitas SDM dengan nilai $\mathrm{t}$ tabel $<\mathrm{t}$ hitung $(1.660<4.478)$ serta nilai signifikansi $0.000 / 2=0<0.05$, maka $\mathrm{H}_{5}$ diterima.

\section{Uji Sobel Tes}

Dalam penelitian ini 2 hipotesis di uji dengan menggunakan sobel tes (Sobel, 1982) yaitu pada hipotesis 6 dan hipotesis 7 dengan hasil sebagi berikut.

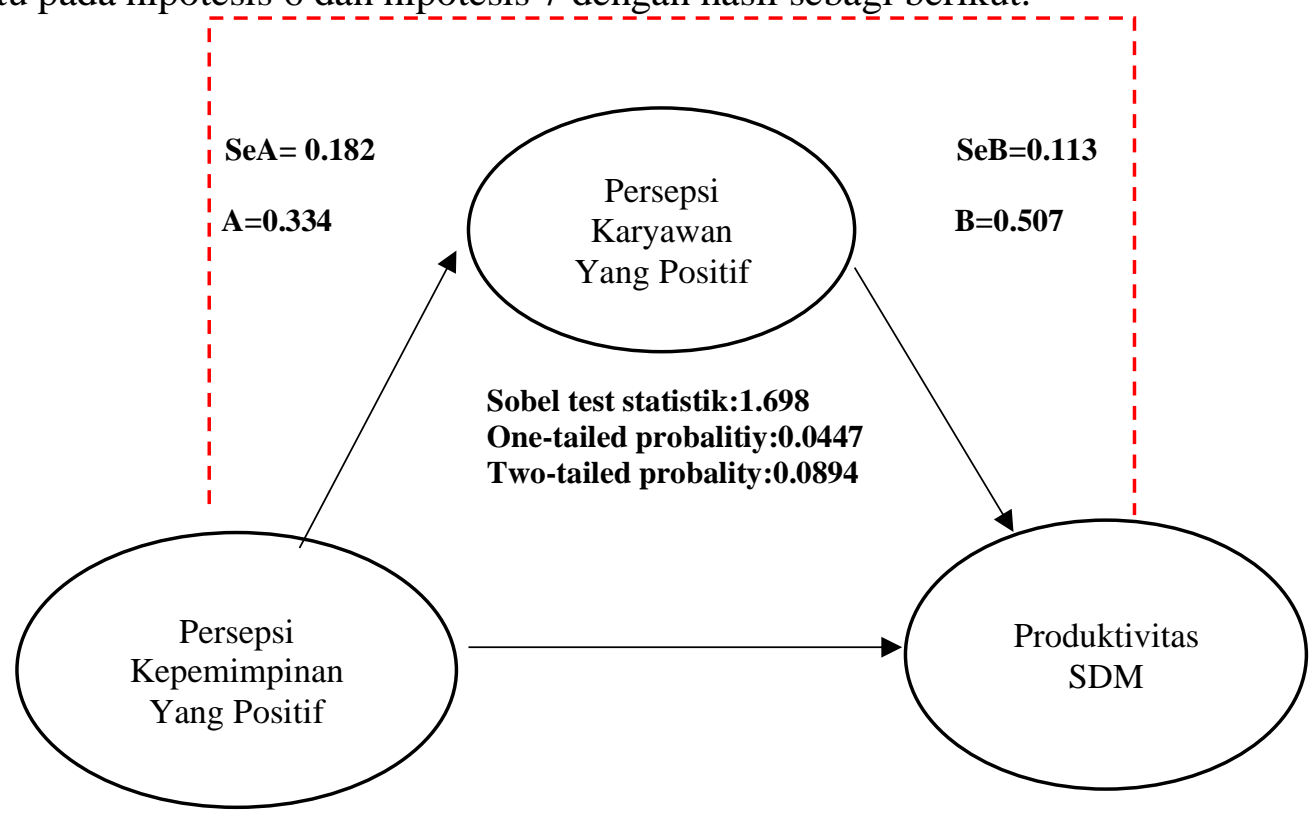

Gambar 2

Keterangan :

Hasil Analisis Sobel Tes Hipotesis 6

$\begin{array}{ll}\mathrm{A} & =0.334 \\ \mathrm{SE}_{\mathrm{A}} & =0.182 \\ \mathrm{~B} & =0.507 \\ \mathrm{SE}_{\mathrm{B}} & =0.113\end{array}$

Sobel test statistic

$=1.698$

One-tailed probability $\quad=0.0447$

Two-tailed probability $=0.0894$

Dari hasil perhitungan sobel test diatas mendapatkan nilai one tailed probability sebesar 0.0447 dengan tingkat signifikansi 5\%, dari hasil tersebut dapat disimpulkan bahwa $0.0447<0,05$ jadi dapat dikatakan bahwa persepsi karyawan yang positif mampu memediasi persepsi kepemimpinan yang positif terhadap produktivitas SDM . 


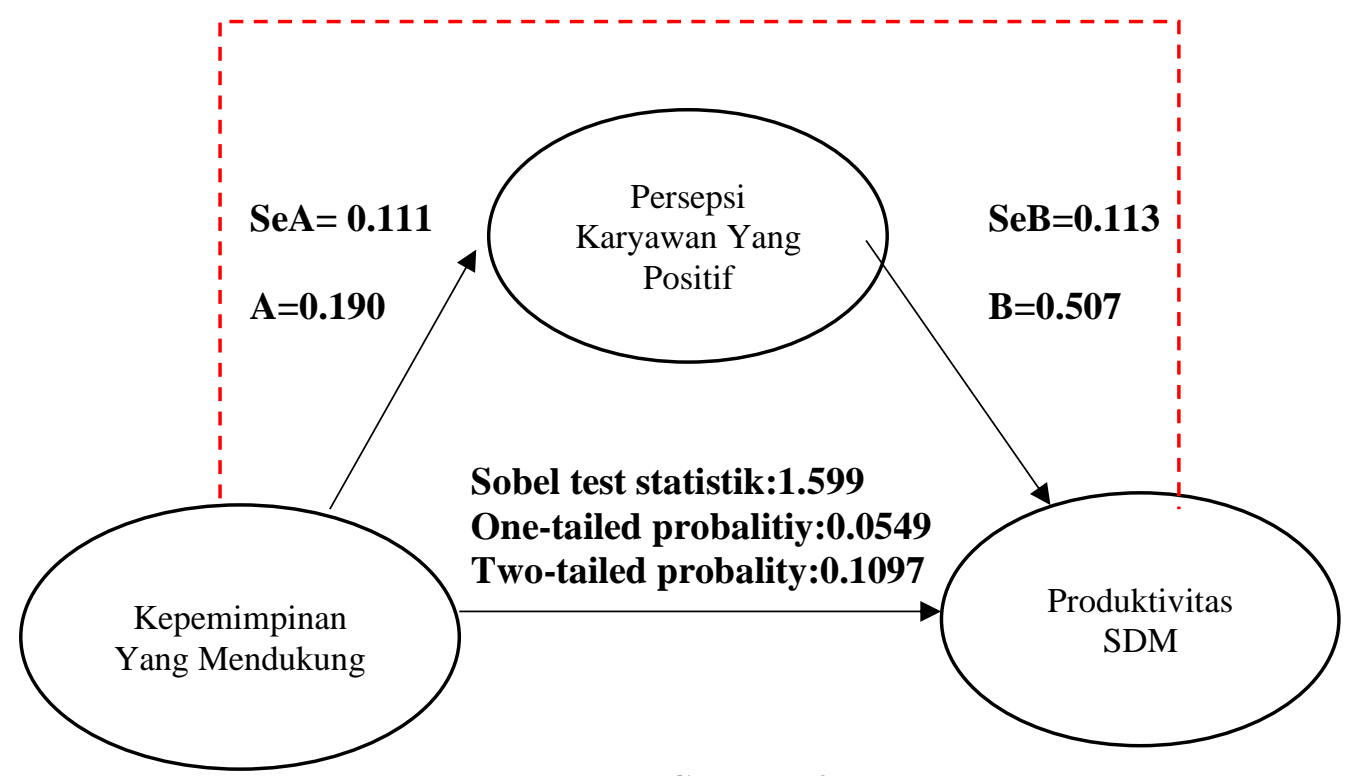

Gambar 3

Keterangan :

Hasil Analisis Sobel Tes Hipotesis 7

$\begin{array}{ll}\mathrm{A} & =0.190 \\ \mathrm{SE}_{\mathrm{A}} & =0.111 \\ \mathrm{~B} & =0.507 \\ \mathrm{SE}_{\mathrm{B}} & =0.113\end{array}$

Sobel test statistic

One-tailed probability $\quad=0.0549$

Two-tailed probability $=0.1097$

Dari hasil perhitungan sobel test diatas mendapatkan nilai one tailed probability sebesar 0.0549 dengan tingkat signifikansi 5\%, dari hasil tersebut dapat disimpulkan bahwa $0.0549>0,05$ jadi dapat dikatakan bahwa persepsi karyawan yang positif tidak mampu memediasi kepemimpinan yang mendukung terhadap produktivitas SDM.

\section{Pengaruh persepsi kepemimpinan yang positif terhadap persepsi karyawan yang positif}

Hasil penelitian yang telah dilakukan oleh peneliti dapat disimpulkan bahwa variabel persepsi kepemimpinan yang positif di uji secara parsial terhadap produktivitas SDM pada karyawan PT.WAHANA KASIH MULIA menghasilkan uji $\mathrm{t}$ sebesar $1.833>\mathrm{t}_{\text {tabel }}$ 1.660 dan nilai sig sebesar $0.070 / 2=0.035<0.05$.berdasarkan data diatas, bahwa variabel persepsi kepemimpinan yang positif dalam penelitian ini berpengaruh secara positif dan signifikan terhadap variabel persepsi karyawan yang positif pada karyawan PT.WAHANA KASIH MULIA.

Persepsi kepemimpinan yang positif merupakan cara seorang pemimpin untuk meningkatkan kualitas kerja karyawan. Peneliti menyimpulkan jika persepsi kepemimpinan yang positif tinggi maka persepsi karyawan yang positif akan meningkat pada karyawan PT.WAHANA KASIH MULIA dan akan memiliki tingkat persepsi kepemimpinan yang positif yang tinggi. Hal ini juga dapat mempengaruhi persepsi karyawan yang positif karena tingkat persepsi kepemimpinan yang positif yang tinggi. 
Berdasarkan pembahasan diatas bahwa hipotesis pertama atau $\mathrm{H}_{1}$ dalam penelitian ini diterima yang artinya variabel persepsi kepemimpinan yang positif berpengaruh positif dan signifikan terhadap persepsi karyawan yang positif pada karyawan PT.WAHANA KASIH MULIA.

\section{Pengaruh kepemimpinan yang mendukung terhadap persepsi karyawan yang positif}

Hasil penelitian yang telah dilakukan oleh peneliti dapat disimpulkan bahwa variabel kepemimpinan yang mendukung di uji secara parsial terhadap persepsi karyawan yang positif pada karyawan PT.WAHANA KASIH MULIA menghasilkan uji t sebesar 1.701 > $\mathrm{t}$ tabel 1.660 dan nilai sig sebesar $0.092 / 2=0.046<0.05$.berdasarkan data diatas, bahwa variabel kepemimpinan yang mendukung dalam penelitian ini berpengaruh secara positif dan signifikan terhadap variabel persepsi karyawan yang positif pada karyawan PT.WAHANA KASIH MULIA.

Kepemimpinan yang mendukung merupakan cara seorang pemimpin untuk mengarahkan kemampuan bawahan dan potensi bawahan agar mau bekerja secara produktif dalam mencapai tujuan yang telah ditentukan sehingga bawahan akan lebih giat dalam melakukan pekerjaan. Peneliti menyimpulkan jika kepemimpinan yang mendukung tinggi maka persepsi karyawan yang positif akan meningkat pada karyawan PT.WAHANA KASIH MULIA. Hal ini juga dapat mempengaruhi persepsi karyawan yang positif karena tingkat kepemimpinan yang mendukung yang tinggi.

Berdasarkan pembahasan diatas bahwa hipotesis kedua atau $\mathrm{H}_{2}$ dalam penelitian ini diterima yang artinya variabel kepemimpinan yang mendukung berpengaruh positif dan signifikan terhadap persepsi karyawan yang positif pada karyawan PT.WAHANA KASIH MULIA.

\section{Pengaruh persepsi kepemimpinan yang positif terhadap produktivitas SDM.}

Hasil penelitian yang telah dilakukan oleh peneliti dapat disimpulkan bahwa variabel persepsi kepemimpinan yang positif di uji secara parsial terhadap produktivitas SDM pada karyawan PT.WAHANA KASIH MULIA menghasilkan uji t sebesar $1.657<\mathrm{t}_{\text {tabel }} 1.660$ dan nilai sig sebesar $0.101 / 2=0.05$.berdasarkan data diatas, bahwa variabel persepsi kepemimpinan yang positif dalam penelitian ini berpengaruh secara positif dan signifikan terhadap variabel produktivitas SDM pada karyawan PT.WAHANA KASIH MULIA.

Persepsi kepemimpinan yang positif merupakan cara seorang pemimpin untuk meningkatkan kualitas kerja karyawan. Peneliti menyimpulkan jika persepsi kepemimpinan yang positif tinggi maka produktivitas SDM akan meningkat pada karyawan PT.WAHANA KASIH MULIA dan akan memiliki tingkat persepsi kepemimpinan yang positif yang tinggi. Hal ini juga dapat mempengaruhi produktivitas SDM karena tingkat persepsi kepemimpinan yang positif yang tinggi.

Berdasarkan pembahasan diatas bahwa hipotesis ketiga atau $\mathrm{H}_{3}$ dalam penelitian ini ditolak yang artinya variabel persepsi kepemimpinan yang positif tidak berpengaruh positif dan signifikan terhadap produktivitas SDM pada karyawan PT.WAHANA KASIH MULIA.

\section{Pengaruh kepemimpinan yang mendukung terhadap produktivitas SDM}

Hasil penelitian yang telah dilakukan oleh peneliti dapat disimpulkan bahwa variabel kepemimpinan yang mendukung di uji secara parsial terhadap produktivitas SDM pada karyawan PT.WAHANA KASIH MULIA menghasilkan uji t sebesar $2.020>t_{\text {tabel }} 1.660$ dan nilai sig sebesar 0.046/2 $=0.023<0.05$. Berdasarkan data diatas, bahwa variabel kepemimpinan yang mendukung dalam penelitian ini berpengaruh secara positif dan 
signifikan terhadap variabel produktivitas SDM pada karyawan PT.WAHANA KASIH MULIA.

Kepemimpinan yang mendukung merupakan cara seorang pemimpin untuk mengarahkan kemampuan bawahan dan potensi bawahan agar mau bekerja secara produktif dalam mencapai tujuan yang telah ditentukan sehingga bawahan akan lebih giat dalam melakukan pekerjaan. Peneliti menyimpulkan jika kepemimpinan yang mendukung tinggi maka produktivitas SDM akan meningkat pada karyawan PT.WAHANA KASIH MULIA. Hal ini juga dapat mempengaruhi produktivitas SDM karena tingkat kepemimpinan yang mendukung yang tinggi. Berdasarkan pembahasan diatas bahwa hipotesis keempat $\mathrm{H}_{4}$ dalam penelitian ini diterima yang artinya variabel kepemimpinan yang mendukung berpengaruh positif dan signifikan terhadap produktivitas SDM pada karyawan PT.WAHANA KASIH MULIA.

\section{Pengaruh persepsi karyawan yang positif terhadap produktivitas SDM.}

Hasil penelitian yang dilakukan oleh peneliti dapat disimpulkan bahwa variabel persepsi karyawan yang positif di uji secara parsial terhadap produktivitas SDM pada karyawan PT.WAHANA KASIH MULIA yang menghasilkan uji t sebesar 4.478> $\mathrm{t}_{\text {tabel }} 1.660$ dan nilai sig sebesar 0.000/2 $=0<0.05$. Berdasarkan data diatas, bahwa variabel persepsi karyawan yang positif dalam penelitian ini berpengaruh secara positif dan signifikan terhadap variabel produktivitas SDM pada karyawan PT.WAHANA KASIH MULIA. Menurut (Bastos \& Barsade, 2020) persepsi karyawan yang positif merupakan cara sikap dan perilaku seorang karyawan dalam melakukan pekerjaan. Dengan adanya dukungan pimpinan terhadap persepsi karyawan yang positif maka akan dapat meningkatkan produktivitas karyawan dalam melakukan pekerjaan. Berdasarkan pembahasan diatas bahwa hipotesis kelima atau $\mathrm{H}_{5}$ dalam penelitian ini diterima yang artinya variabel persepsi karyawan yang positif berpengaruh positif dan signifikan terhadap produktivitas SDM pada karyawan PT.WAHANA KASIH MULIA.

\section{Persepsi kepemimpinan yang positif dan produktivitas SDM dengan persepsi karyawan yang positif sebagai variabel intervening.}

Berdasarkan data yang ada di lapangan bahwa persepsi kepemimpinan yang positif dan produktivitas SDM dengan persepsi karyawan yang positif sebagai variabel intervening membuktikan bahwa terdapat pengaruh yang positif dan signifikan.

Dengan demikian persepsi kepemimpinan yang positif dapat diintervening melalui persepsi karyawan yang positif terhadap produktivitas SDM dibuktikan dengan hasil olah data Sobel Test dengan nilai one-tailed probability sebesar $0.0447<$ 0.05 sehingga dapat disimpulkan persepi kepemimpinan yang positif dapat diintervening memalui persepsi karyawan yang positif terhadap produktivitas SDM.

\section{Kepemimpinan yang mendukung dan produktivitas SDM dengan persepsi karyawan yang positif sebagai variabel intervening.}

Berdasarkan data yang ada dilapangan bahwa kepemimpinan yang mendukung dan produktivitas SDM denganpersepsi karyawan yang positif sebagai variabel intervening tidak berpengaruh positif dan signifikan.

Dengan demikian kepemimpinan yang mendukung dapat diintervening melalui persepsi karyawan yang positif terhadap produktivitas SDM dibuktikan dengan hasil olah data Sobel Test dengan nilai one-tailed probability sebesar $0.0549>0.05$, 
sehingga dapat disimpulkan kepemimpinan yang mendukung tidak dapat diintervening melalui persepsi karyawan yang positif terhadap produktivitas SDM.

\section{PENUTUP \\ Kesimpulan}

Terdapat pengaruh yang positif dan signifikan persepsi kepemimpinan yang positif terhadap persepsi karyawan pada karyawan PT.WAHANA KASIHMULIA. Terdapat pengaruh yang positif dan signifikan kepemimpinan yang mendukung terhadap persepsi karyawan yang positif pada karyawan PT.WAHANA KASIH MULIA. Terdapat pengaruh yang tidak positif dan signifikan Persepsi kepemimpinan yang positif terhadap produktivitas pada karyawan PT.WAHANA KASIH MULIA. Terdapat pengaruh yang positif dan signifikan kepemimpinan yang mendukung terhadap produktivitas SDM pada karyawan PT.WAHANA KASIH MULIA. Terdapat pengaruh yang positif dan signifikan persepsi karyawan yang positif terhadap produktivitas SDM pada karyawan PT.WAHANA KASIH MULIA Terdapat pengaruh yang positif dan signifikan persepsi kepemimpinan yang positif terhadap produktivitas SDM dengan persepsi karyawan yang positif sebagai variabel intervening. Terdapat pengaruh yang positif dan signifikan kepemimpinan yang mendukung terhadap produktivitas SDM dengan persepsi karyawan yang positif sebagai variabel intervening.

\section{Saran}

PT.WAHANA KASIH MULIA harus memperhatikan persepsi kepemimpinan yang positif karena variabel tersebut berpengaruh positif dan signifikan terhadap produktivitas SDM. Pelatihan yang dilakukan oleh PT.WAHANA KASIH MULIA sudah sangat baik, akan tetapi ada baiknya jika PT.WAHANA KASIH MULIA dapat mempertahankan program-program pelatihan saat ini. Tentunya produktivitas SDM akan lebih baik apabila dapat meningkatkan atau memperbanyak pelatihan yang sesuai dengan job specification agar kualitas pengetahuan dan keterampilan yang dimiliki karyawan dapat bertahan dari waktu ke waktu.

Pemimpin dan rekan kerja hendaknya harus saling memberi motivasi dengan cara memberi penghargaan kepada pegawai yang berprestasi, pegawai yang bekerja dengan rajin dan memberikan sanksi tegas kepada pegawai yang sering terlambat datang, hal tersebut di maksud supaya karyawan dapat bekerja sesuai dengan apa yang telah ditetapkan dalam suatu perusahan sehingga dapat meningkatkan kinerja karyawan, selai itu PT.WAHANA KASIH MULIA juga harus meningkatkan kompetensi karyawan dengan melakukan pelatihan guna dapat meningkatkan pengetahuan, keterampilan kerja dan sikap. Sehingga karyawan mendapat ilmu tambahan yang berguna di masa sekarang maupun di masa yang akan datang.

Penelitian ini dapat dilakukan kembali dengan objek penelitian yang berbeda serta dengan item pertanyaan pada kuesioner yang berbeda. Bagi peneliti berikutnya dapat dimanfaatkan sebagai bahan rujukan dalam melakukan penelitian yang berkaitan dengan persepsi kepemimpinan yang positif, kepemimpinan yang mendukung, persepsi karyawan yang mendukung dan berpengaruh terhadap produktivitas SDM. 


\section{DAFTAR PUSTAKA}

Anggraeni, Y., \& Santosa, T. E. C. (2013). Pengaruh Kepemimpinan Transformasional Terhadap Kepuasan Kerja Karyawan. Jurnal Dinamika Ekonomi \& Bisnis, 10(1), 5168.

Bastos, W., \& Barsade, S. G. (2020). A new look at employee happiness: How employees' perceptions of a job as offering experiences versus objects to customers influence job-related happiness. Organizational Behavior and Human Decision Processes, 161(August 2018), 176-187. https://doi.org/10.1016/j.obhdp.2020.06.003

Euis, O. (2008). KEPEMIMPINAN YANG EFEKTIF DAN PERUBAHAN ORGANISASI Oleh : Euis Soliha dan Hersugondo Fakultas Ekonomi Universitas Stikubank Semarang. Fokus Ekonomi, 7(2), 83-93. Retrieved from http://download.portalgaruda.org/article.php?article $=110046 \&$ val $=550$

Findarti, F. R. (2016). Pengaruh Pengembangan Sumber Daya Manusia Terhadap Kinerja Pegawai Pada Kantor Badan Kepegawaian Daerah Provinsi Kalimantan Timur. EJournal Ilmu Administrasi Bisnis, 4(5), 937-946.

Jufrizen, J., \& Lubis, A. S. P. (2020). Pengaruh Kepemimpinan Transformasional dan Kepemimpinan Transaksional terhadap Kinerja Pegawai Dengan Locus Of Control Sebagai Variabel Moderating. Maneggio: Jurnal Ilmiah Magister Manajemen, 3(1), 41-59. https://doi.org/10.30596/maneggio.v3i1.4874

Masruroh, I. (2019). Pengaruh Model Snowball Throwing Terhadap Hasil Belajar Siswa Pada Mata Pelajaran IPA. Bioedusiana, 4(2), 1-8. https://doi.org/10.34289/292828

Mohammadian, M., Arayesh, B., Mohammadian, M., Azizpour, L., \& Zanganeh, M. (2011). An investigation into effective factors on human resources productivity. (Case study: Region 11, Islamic Azad University, Iran). Australian Journal of Basic and Applied Sciences, 5(6), 760-764. https://doi.org/10.1016/j.sbspro.2015.09.089

Nasron, \& Astuti, T. B. (2011). Faktor-Faktor Yang Mempengaruhi Produktivitas ( Studi Pada Karyawan Bagian Produksi PT Nusantara Building Industries ) The Factors That Influence The Productivity ( A Study Of The Employees Of Production Department At PT Nusantara Building Industries ). Sekolah Tinggi Ilmu Ekonomi Widya Manggala, 1(1), 1-23. Retrieved from file:///D:/PROPOSAL B/nasron.pdf\%0D

Nathan, A. J., \& Scobell, A. (2012). How China sees America. Foreign Affairs, 91(5), 72 80. https://doi.org/10.1017/CBO9781107415324.004

Nurcahyo, B., \& Riskayanto, R. (2018). Analisis Dampak Penciptaan Brand Image Dan Aktifitas Word of Mouth (Wom) Pada Penguatan Keputusan Pembelian Produk Fashion. Jurnal Nusantara Aplikasi Manajemen Bisnis, 3(1), 14. https://doi.org/10.29407/nusamba.v3i1.12026

Prajitno, S. B. (2008). Pengetahuan, metode ilmiah, dan teori. Jurnal Penelitian Publik, $1-29$.

Singh, A., \& Misra, S. C. (2020). A Dominance based Rough Set analysis for investigating employee perception of safety at workplace and safety compliance. Safety Science, 127(March), 104702. https://doi.org/10.1016/j.ssci.2020.104702

Sobel, M. E. (1982). Asymptotic Confidence Intervals for Indirect Effects in Structural 
Equation Models. Sociological Methodology, 13(1982), 290. https://doi.org/10.2307/270723

Syafei, M., Fahmi, I., \& Hubeis, A. V. S. (2016). Faktor-Faktor Yang Memengaruhi Kinerja Karyawan Pt Pul Logistics Indonesia. Jurnal Aplikasi Bisnis Dan Manajemen, (September), 217-229. https://doi.org/10.17358/jabm.2.3.217

Wisastra, P. I. Y., \& Sagala, E. J. (2016). Pengaruh Pelatihan Terhadap Kompetensi Karyawan Pt. Len Industri (Persero) Bandung. Matrik: Jurnal Manajemen, Strategi $\begin{array}{llll}\text { Bisnis Dan } & \text { Kewirausahaan, }\end{array}$ https://doi.org/10.24843/matrik:jmbk.2016.v10.i02.p01 